\title{
Caffeoylquinic acid induces ATP production and energy metabolism in human neurotypic SH-SY5Y cells
}

\author{
Kazunori Sasaki ${ }^{\mathrm{a}}$, Junkyu Han ${ }^{\mathrm{a}, \mathrm{b}}$, Hideyuki Shigemori ${ }^{\mathrm{a}}$ and Hiroko Isoda ${ }^{\mathrm{a}, \mathrm{b}, *}$ \\ ${ }^{\mathrm{a}}$ Graduate School of Life and Environmental Sciences, University of Tsukuba, Tennodai, Tsukuba, Ibaraki, Japan \\ ${ }^{\mathrm{b}}$ Alliance for Research on North Africa (ARENA), University of Tsukuba, Tennodai, Tsukuba, Ibaraki, Japan
}

\begin{abstract}
Caffeoylquinic acid (CQA) derivatives are polyphenolic compounds found in wide variety of plants. Previously, we have demonstrated that di-CQA and tri-CQA may be neuroprotective through their ability to promote intracellular adenosine-5'triphosphate (ATP) generation and by up-regulation of glycolytic enzyme expression. In the present study we have investigated the effect of di-CQA and tri-CQA on energy metabolism in SH-SY5Y cells using a metabolomic approach. Results indicate that di-CQA treatment of SH-SY5Y cells significantly increases the production of an array of glycolysis metabolites and tricarboxylic acid (TCA) cycle metabolites, including acetyl-CoA, succinic acid, fumaric acid, and malic acid. Tri-CQA treatment was also observed to increase the levels of all glycolysis and TCA cycle metabolites and evoked a stronger effect than that of di-CQA. In addition to their effects on glycolytic metabolites, di-CQA and tri-CQA exposure also induced a significant increase in the production of ATP, ADP, GTP, and GDP. Our results suggest that CQA-induction of intracellular ATP synthesis is mediated by the activation of central metabolic pathways including the activation of glycolysis and the TCA cycle.
\end{abstract}

Keywords: di-CQA, tri-CQA, ageing, metabolome analysis, glycolysis, TCA cycle

\section{Introduction}

Ageing and senescence are complex processes that dramatically impact on human health and society. Elucidation of the basic molecular mechanisms underlying the progressive decline in cellular function that accompanies ageing and eventually leads to senescence will have an immediate impact on the design of novel interventions that could reduce or delay age-related deterioration in humans. Alzheimer's disease (AD) is a major age-related neurodegenerative disorder and the most common form of dementia. During aging there is a progressive accumulation of damaged biomolecules

*Corresponding author: Professor Hiroko Isoda $(\mathrm{PhD})$, Graduate School of Life and Environmental Sciences, University of Tsukuba, Alliance for Research on North Africa (ARENA), University of Tsukuba, 1-1-1 Tennodai, Tsukuba, Ibaraki 305-8572, Japan. Tel.: +81 29853 5775; Fax: +81 29853 5776; E-mail: isoda.hiroko.ga@u.tsukuba.ac.jp. and impaired energy metabolism in cells. Furthermore, mitochondrial and their dysfunction are considered a key factor of with regards to ageing and longevity.

Mitochondria play a central role in the energy metabolism, where the oxidation of carbohydrates, lipids and amino acids generates adenosine- $5^{\prime}$ triphosphate (ATP). Even though the process of oxidative phosphorylation is efficient, a small percentage of electrons may "leak" from the electron transport chain, particularly from complexes I and III, during normal respiration forming reactive oxygen species (ROS) [1]. ROS produced within mitochondria represent almost $90 \%$ of the total ROS produced in the cell, meaning that mitochondria are a prime target for oxidative damage, something that has led to the concept of the 'mitochondrial theory of aging' [2]. ROS generation in mitochondria may lead to neuronal damage through oxidative stress and energy deficiency [3]. Indeed, mitochondrial dysfunction and oxidative 
damage are known to play key roles in pathogenesis of numerous neurological disorders such as Parkinson's disease, AD, Huntington's disease, amyotrophic lateral sclerosis, Wilson's disease, Friedreich's ataxia, multiple sclerosis, mitochondrial encephalomyopathies, and a number of inherited disorders of the mitochondrial genome [4-7].

Polyphenols are naturally occurring compounds widely distributed in higher plants, making them an integral part of the human diet, in particular fruits, vegetables and some beverages, such as tea, coffee, fruit juices, and red wine [8]. Phenolic compounds have received much interest as numerous epidemiological studies have suggested associations between the consumption of polyphenol-rich foods or beverages and the prevention of certain chronic diseases such as cardiovascular disease [9-11]. For example, flavonoidrich tea, cacao, and orange have been demonstrated to exert beneficial effects on vascular function in vitro studies and human clinical trials [9-11]. A suggested mechanism for their actions includes their antioxidant potential [12] as they have been demonstrated to influence various oxidative stress biomarkers [13]. Polyphenols may protect cells against oxidative damage through free radical scavenging, or more likely the activation of oxidative enzyme defence system and as such may also be capable of modulating ROS generation and ATP production in mitochondria. The up-regulation of such defence enzymes are likely to be related to their capacity to interact with cellular signalling pathways that regulate transcription factors and consequently the expression of genes and proteins $[10$, 14].

Caffeoylquinic acid (CQA) derivatives are natural polyphenolic compounds that may be isolated from a variety of plants, such as apple, pear, berries, and aubergine [15]. However, the major source of CQAs in the human diet is coffee, with a single cup containing between 70-350 mg caffeoylquinic acid [15]. CQAs possess a broad range of pharmacological properties, including antioxidant, hepatoprotectant, antibacterial, anticancer properties. Previously, we have observed that di-CQA and tri-CQA have a potent ability to inhibit amyloid beta-induced neurotoxicity in SHSY5Y cells (an established in vitro model of AD). Additionally, both compounds up-regulated glycolytic enzymes at the mRNA level [16, 17], and induced a significant increase of ATP production, which was greater for tri-CQA than di-CQA [16-18]. In the current study, we aimed to deepen our understanding of the mechanism of di-CQA and tri-CQA-induction of ATP synthesis in SH-SY5Y cells using a metabolomic approach.

\section{Materials and methods}

\subsection{Purification of di-CQA}

Purple sweet potato (PSP) was harvested in Kagoshima prefecture, Japan and was steamed for 40 minutes, minced, and then dried using a double drum type drier. The dried powder of PSP then was crushed in $80 \%$ ethanol, filtered, and concentrated using an evaporator. The PSP extract was then divided into fractions containing phenolic compounds or anthocyanins, using the ethyl acetate liquid/liquid extraction method [19]. Anthocyanin-free PSP phenolic fraction was then used in this study. The chemical composition profile of this extract was performed using High Phase Liquid Chromatography (HPLC) analysis according to the method of Okuno et al. [20] and Shimozono et al. [21]. HPLC analysis was performed using D, Cadenza CD-18 column $(5 \times 4.6$ mm i.d.) (Imtakt Corp., Kyoto, Japan). A binary phase distilled water- $0.1 \% \mathrm{H}_{3} \mathrm{PO}_{4}$ (solvent A) and acetonitrile $100 \%$ (solvent B) was used. With a flow rate of $1 \mathrm{~mL} / \mathrm{min}$, analytes were eluted from the column using this gradient: B solution 2 to $19 \%$ (0 to 8 minutes, linear concentration gradient), 19 to $52 \%$ (8 to 16 minutes, linear concentration gradient), $100 \%$ (16.01 to 20 minutes), $2 \%$ (20.01 to 27 minutes). Peak spectra were recorded at $326 \mathrm{~nm}$ using UV detector. di-CQAs contained in purple sweet potato flesh were identified as 3,4-diCQA, 3,5-di-CQA (Fig. 1), and 4,5-di-CQA according to their retention time and comparison with authentic standards [22].

\subsection{Purification of tri-CQA}

Brazilian propolis $(50 \mathrm{~g})$ was extracted with $450 \mathrm{~mL}$ $\mathrm{MeOH}$ and evaporated to dryness in vacuo at $30^{\circ} \mathrm{C}$. The $\mathrm{MeOH}$ extract was partitioned with EtOAc $(1 \mathrm{~L} \times 3)$ and $\mathrm{H}_{2} \mathrm{O}(1 \mathrm{~L})$. The EtOAc-soluble portion was divided into six fractions using silica gel column chromatography $\left(4.4 \times 35 \mathrm{~cm}, \mathrm{CHCl}_{3} / \mathrm{MeOH}, 95: 5\right.$ to $0: 100)$. A fraction eluted with $\mathrm{CHCl}_{3} / \mathrm{MeOH}(50: 50)$ was divided subjected to ODS column chromatography $\left(1.1 \times 35 \mathrm{~cm}, \mathrm{MeOH} / \mathrm{H}_{2} \mathrm{O}, 30: 70\right.$ to $\left.100: 0\right)$. A 
<smiles>O=C(O)CC(O)(CC(O)C(O)OC(=O)/C=C/c1ccc(O)c(O)c1)C(=O)O</smiles><smiles>[B]C(CCC(O)(C(=O)O)C(=O)OC(=O)/C=C/c1ccc(O)c(O)c1)OC(=O)/C=C/c1ccc(O)c(O)c1</smiles>

Fig. 1. Structure of 3,5-di-caffeoylquinic acid (A) and 3,4,5-tricaffeoylquinic acid (B).

fraction eluted with $\mathrm{MeOH} / \mathrm{H}_{2} \mathrm{O}(100: 0)$ was applied to a $\mathrm{C}_{18}$ Sep-Pak cartridge (Waters, $\mathrm{MeOH} / \mathrm{H}_{2} \mathrm{O}$, $70: 30$ to $100: 0$ ) (Waters Associates, Inc., USA.) to give tri-CQA (Fig. 1) [18]. The tri-CQAs contained in propolis were identified as 3,4,5-tri-CQA using ${ }^{1} \mathrm{H}-\mathrm{NMR}$ and ${ }^{13} \mathrm{C}$-NMR spectrum of 3,4,5-tri-CQA standard as explained in our previous study [17]. For each assay, tri-CQA was dissolved in $\mathrm{EtOH}$ and added to cell culture medium.

\subsection{Cell culture}

The human neurotypic SH-SY5Y cell line was obtained from American Type Culture Collection
(ATCC). SH-SY5Y cells were cultured in $100 \mathrm{~mm}$ petri dish or in 96-well plates depending on the purpose, with a $1: 1(\mathrm{v} / \mathrm{v})$ mixture of Dulbecco's minimum essential medium (Sigma, USA) and Ham's F-12 nutrient mixture (Sigma, USA) supplemented with $15 \%$ foetal bovine serum (Sigma, USA), and 1\% penicillin $(5,000 \mu \mathrm{g} / \mathrm{mL})$-streptomycin $(5,000 \mathrm{IU} / \mathrm{mL})$ solution (ICN Biomedicals, Japan) at $37^{\circ} \mathrm{C}$ in a $95 \%$ humidified air-5\% $\mathrm{CO}_{2}$ incubator. A serum-free Eagle's minimum essential medium (OPTI-MEM; Gibco, Tokyo, Japan) was used to culture the cells for the metabolome analysis.

\subsection{Metabolome analysis}

SH-SY5Y cells $\left(2 \times 10^{5}\right.$ cells $\left./ \mathrm{mL}\right)$ were treated with $10 \mu \mathrm{M}$ of di-CQA, or $20 \mu \mathrm{M}$ of tri-CQA before being subjected to metabolite extraction using $1 \mathrm{~mL}$ methanol containing $10 \mu \mathrm{M}$ of internal standards. Following this, $1 \mathrm{ml}$ chloroform and $400 \mu \mathrm{L}$ of milliQ water were added and the sample centrifuged at $2300 \times g$ at $4^{\circ} \mathrm{C}$ for $5 \mathrm{~min}$. After centrifugation, the aqueous phase was transferred to a filtration tube (Millipore, USA) and centrifuged at $9100 \times g$ at $4^{\circ} \mathrm{C}$ for $120 \mathrm{~min}$. Filtrates were dried and dissolved in $50 \mu \mathrm{L}$ of milliQ water. Metabolome analysis was performed by CE-TOFMS (Agilent Technologies, Inc., USA).

\subsection{Instrumentation of CE-TOFMS}

CE-ToFMS was carried out using an Agilent CE Capillary Electrophoresis System equipped with an Agilent 6210 Time of Flight mass spectrometer, Agilent 1100 isocratic HPLC pump, Agilent G1603A CE-MS adapter kit, and Agilent G1607A CE-ESIMS sprayer kit (Agilent Technologies, Waldbronn, Germany). The system was controlled by Agilent G2201AA ChemStation software version B.03.01 for CE (Agilent Technologies, Waldbronn, Germany).

Cationic metabolites were analysed with a fused silica capillary $(50 \mu \mathrm{M}$ i.d. $\times 80 \mathrm{~cm}$ total length), with Cation Buffer Solution (Human Metabolome Technologies, Tokyo, Japan) as the electrolyte. The sample was injected at a pressure of $50 \mathrm{mbar}$ for $10 \mathrm{sec}$ (approximately $10 \mathrm{~nL}$ ). The applied voltage was set at $27 \mathrm{kV}$. Electrospray ionization-mass spectrometry (ESI-MS) was conducted in the positive ion mode, and the capillary voltage was set at $4,000 \mathrm{~V}$. The spectrometer was scanned from $\mathrm{m} / \mathrm{z} 50$ to 1,000 . Other conditions 
were as in the cation analysis [23]. Anionic metabolites were analysed with a fused silica capillary $(50 \mu \mathrm{M}$ i.d. $\times 80 \mathrm{~cm}$ total length), with Anion Buffer Solution (Human Metabolome Technologies, Tokyo, Japan) as the electrolyte. The sample was injected at a pressure of $50 \mathrm{mbar}$ for $25 \mathrm{sec}$ (approximately $25 \mathrm{~nL}$ ). The applied voltage was set at $30 \mathrm{kV}$. ESI-MS was conducted in the negative ion mode, and the capillary voltage was set at $3,500 \mathrm{~V}$. The spectrometer was scanned from $50 \mathrm{~m} / \mathrm{z}$ to 1,000 . Other conditions were as in the anion analysis [24].

Raw data obtained by CE-ToFMS were processed with MasterHands [25]. Signal peaks corresponding to isotopomers of 108 compounds including the intermediates of glycolytic system, the intermediates of nucleotide (TCA) cycle, and amino acids were extracted. And then their migration time (MT) was normalized using those of the internal standards. The resultant relative area values were further normalized by sample amount.

\section{Results}

\section{1. di-CQA and tri-CQA effects on energy metabolism}

Both di-CQA and tri-CQA lead to the increased production of metabolites related to glycolysis (Table 1) and TCA cycle (Table 2) compared to vehicle treated cells. Metabolic pathway maps indicated that the changes in the concentrations of metabolites involved in glycolysis and TCA cycle (Figs. 2 and 3). The glycolysis metabolites: glucose 6phosphate (G6P), fructose 6-phosphate (F6P), fructose 1,6-diphosphate (F1,6), Glyceraldehyde 3-phosphate, 3-phosphoglyceric acid (3-PG), 2-phosphoglyceric acid (2-PG), phosphoenolpyruvic acid (PEP), were markedly increased in cells exposed to $10 \mu \mathrm{M}$ of diCQA or $20 \mu \mathrm{M}$ of tri-CQA treatment compared to vehicle treated cells (Fig. 1). Moreover, TCA cycle metabolites acetyl-CoA_divalent (AcCoA), succinic acid, fumaric acid, and malic acid were also increased in both di-CQA and tri-CQA treatment group (Table 2), with tri-CQA inducing a greater effect than di-CQA. In addition, although di-CQA had no major influence on the level of lactic acid in cells, tri-CQA markedly increased levels of this metabolite (Table 1).

The increases in some of the metabolites by di-CQA and tri-CQA were not time dependent. For example,
di-CQA induced peak levels of G6P, F6P, FBP, glyceraldehyde 3-phosphate, 3-PGA, and 2-PGA at $12 \mathrm{~h}$, with levels decreased or unchanged at $24 \mathrm{~h}$. Pyruvic acid was not detected in di-CQA treated cells and PEP was only slightly increased (Table 1 and Fig. 1). With respect to TCA cycle metabolites, AcCoA, succinic acid, fumaric acid, and malic acid were moderately increased, whereas di-CQA treatment slightly reduced the levels of citric acid, cis-aconitic acid, and isocitric acid compared to the control cells (Table 2). In contrast, tri-CQA generally led to bigger increases in glycolysis metabolites, with G6P and F6P peaking at $24 \mathrm{~h}$, FBP and pyruvic acid peaking at $6 \mathrm{~h}$ and other metabolites peaking at $12 \mathrm{~h}$ (Table 1 ). TCA cycle metabolites AcCoA, fumaric acid and malic acid peaked at $12 \mathrm{~h}$ and $24 \mathrm{~h}$ and other TCA cycle metabolites all peaked value at $6 \mathrm{~h}$ (Table 2).

\section{2. di-CQA and tri-CQA induced changes in nucleotides}

The levels of the nucleotides: ATP, ADP, GTP, and GDP were all increased following exposure to di-CQA or tri-CQA compared to the non-treated cells at $24 \mathrm{~h}$ (Table 3). The amount of AMP was increased in triCQA group, although to a lesser degree by di-CQA. Moreover, compared to di-CQA and control group, the amount of ADP, GTP, and GDP were lower in di-CQA treated group. di-CQA and tri-CQA induced similar levels of ATP production.

\section{Discussion}

In the present study, the effect of di-CQA and triCQA on energy metabolism in SH-SY5Y cells was investigated using metabolomic approach. The concentrations used in the current study were based on those previously determined to enhance ATP synthesis and reverse amyloid beta-induced cytotoxicity in $\mathrm{SH}$ SY5Y cells $[16,17]$. Cell metabolome profiling may contribute to better understanding of cellular molecular mechanisms with capillary electrophoresis mass spectrometry (CE-MS) emerging and powerful tool for the analysis of large numbers of metabolites [26, 27]. The major advantages of CE-MS are that this methodology exhibits extremely high resolution and previous studies report that CE-MS is useful for the determination of several anionic metabolites [28, 29], whilst generating 

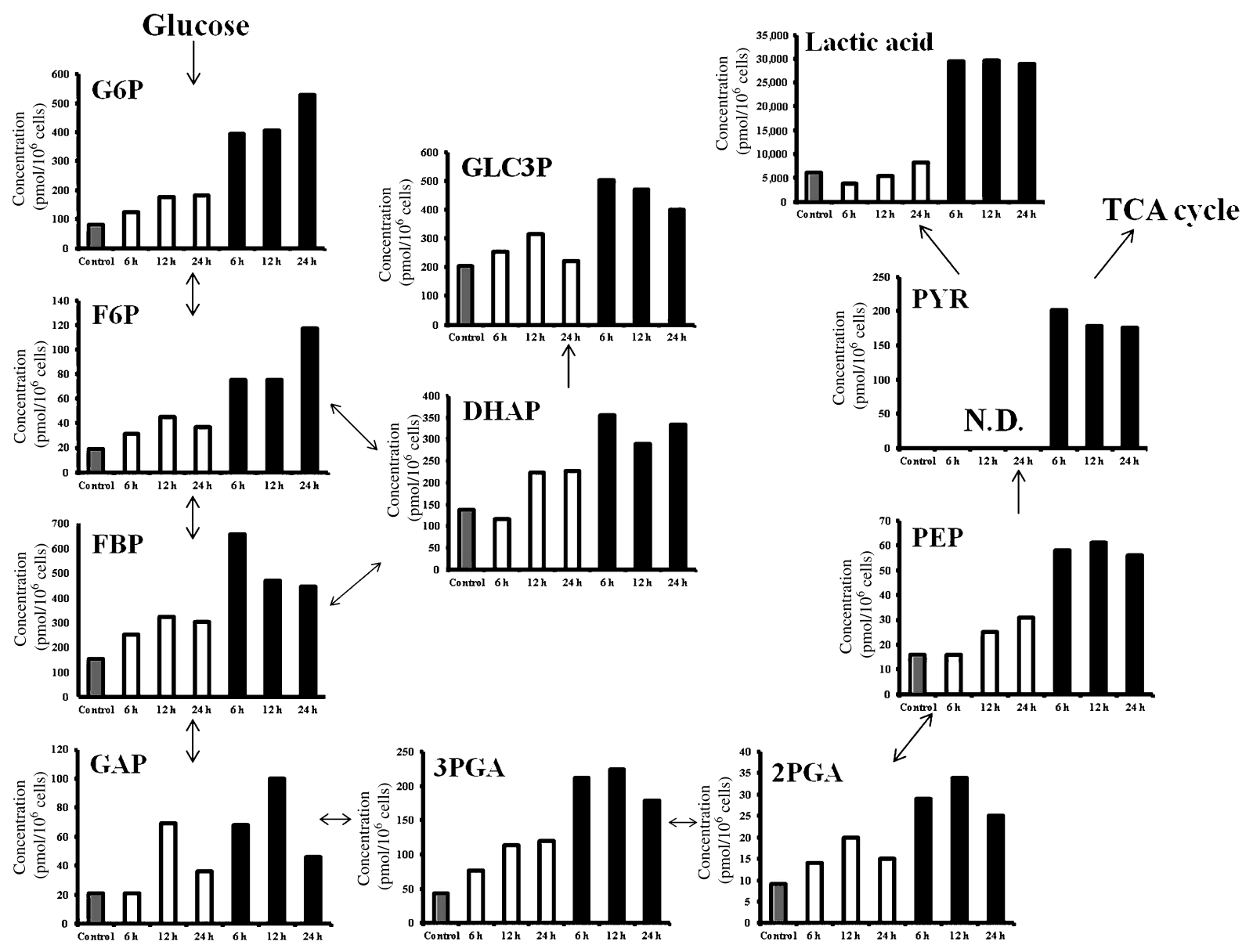

Fig. 2. Metabolome data map of cycle metabolites related glycolysis in non-treated cells (grey bar), $10 \mu \mathrm{M}$ of di-caffeoylquinic (CQA) acidtreated cells (white bars), and $20 \mu \mathrm{M}$ of tri-CQA-treated cells (black bars). Columns show amounts of metabolites (pmol/10 ${ }^{6}$ cells) determined through Capillary electrophoresis time-of-flight mass spectrometry (CE-ToFMS). Abbreviations: G6P, Glucose 6-phosphate; F6P, Fructose 6-phosphate; FBP, Fructose 1,6-diphosphate; GLC3P, Glycerol 3-phosphate; DHAP, Dihydroxyacetone phosphate; GAP, Glyceraldehyde 3-phosphate; 3-PGA, 3-Phosphoglyceric acid; 2-PGA, 2-Phosphoglyceric acid; PEP, Phosphoenolpyruvic acid; PYR, Pyruvic acid.

data that are highly reproducible [30,31]. We have previously demonstrated reproducibility using several in vitro models with our previous studies indicting that 3,5-di-CQA [16] and 3,4,5-tri-CQA exposed leads to stable, reproducible effects on neuroprotective and the up-regulation of glycolytic enzymes [17].

Many clinical studies support the notion that a decrease in cerebral glucose metabolism is an early and consistent manifestation of AD pathophysiology, occurring prior to the occurrence of any overt pathology or severe brain atrophy $[32,33]$. As such, changes in energy metabolism in the brain appear to be critical to disease pathology rather than merely a consequence of neuronal loss. Neurons have a relatively high requirement for cellular ATP [34] in order that various neuronal processes, such as the firing of action potentials, neurotransmission, and ion homeostasis may be sustained. Age-related declines in energy metabolism may contribute to cognitive declines associated with aging $[35,36]$, which may be further exacerbated in selective regions of the brain in $\mathrm{AD}$ and $\mathrm{PD}[37,38]$. To study changes in cellular energy metabolism in response to CQA exposure, we assessed the production of glycolysis and TCA cycle related metabolites. Generally, metabolite levels relating to both glycolysis and the TCA cycle were increased in response to di-CQA and tri-CQA exposure, suggesting that these compounds are capable of up-regulating energy 
Table 1

Comparison of amount of identified metabolites related glycolysis in non-treated cells versus di-caffeoylquinic acid (CQA)-treated cells (10 $\mu \mathrm{M})$, and tri-CQA-treated cells $(20 \mu \mathrm{M})$ in SH-SY5Y. Concentrations of metabolites (pmol/10 6 cells) were identified by Capillary electrophoresis time-of-flight mass spectrometry (CE-ToFMS)

\begin{tabular}{|c|c|c|c|c|c|c|c|}
\hline \multirow[t]{3}{*}{ Metabolites } & \multirow[t]{3}{*}{ Control } & \multicolumn{6}{|c|}{ Concentration (pmol/10 $0^{6}$ cells) } \\
\hline & & \multicolumn{3}{|c|}{ di-CQA treatment group } & \multicolumn{3}{|c|}{ tri-CQA treatment group } \\
\hline & & 6 hour & 12 hour & 24 hour & 6 hour & 12 hour & 24 hour \\
\hline G6P & 80 & 124 & 175 & 183 & 393 & 406 & 528 \\
\hline F6P & 19 & 31 & 45 & 37 & 75 & 75 & 117 \\
\hline FBP & 155 & 252 & 324 & 302 & 656 & 468 & 447 \\
\hline GLC3P & 205 & 255 & 315 & 222 & 502 & 471 & 400 \\
\hline DHAP & 137 & 116 & 224 & 226 & 356 & 290 & 334 \\
\hline GAP & 21 & 21 & 69 & 36 & 68 & 100 & 46 \\
\hline 3-PGA & 44 & 77 & 114 & 120 & 212 & 224 & 179 \\
\hline 2-PGA & 9.1 & 14 & 20 & 15 & 29 & 34 & 25 \\
\hline PEP & 16 & 16 & 25 & 31 & 58 & 61 & 56 \\
\hline PYR & N.D. & N.D. & N.D. & N.D. & 202 & 178 & 176 \\
\hline Lactic acid & 6,188 & 3,847 & 5,415 & 8,296 & 29,422 & 29,702 & 28,962 \\
\hline
\end{tabular}

Abbreviations: G6P, Glucose 6-phosphate; F6P, Fructose 6-phosphate; FBP, Fructose 1,6-diphosphate; GLC3P, Glycerol 3-phosphate; DHAP, Dihydroxyacetone phosphate; GAP, Glyceraldehyde 3-phosphate; 3-PGA, 3-Phosphoglyceric acid; 2-PGA, 2-Phosphoglyceric acid; PEP, Phosphoenolpyruvic acid; PYR, Pyruvic acid.

Table 2

Quantification of tricarboxylic acid (TCA) cycle metabolites in non-treated cells versus di-caffeoylquinic acid (CQA)-treated cells (10 $\mu$ M), and tri-CQA-treated cells $(20 \mu \mathrm{M})$ in SH-SY5Y. Concentrations of metabolites ( $\mathrm{pmol} / 10^{6}$ cells) were identified by Capillary electrophoresis time-of-flight mass spectrometry (CE-ToFMS)

\begin{tabular}{|c|c|c|c|c|c|c|c|}
\hline \multirow[t]{3}{*}{ Metabolites } & \multirow[t]{3}{*}{ Control } & \multicolumn{6}{|c|}{ Concentration (pmol/10 6 cells) } \\
\hline & & \multicolumn{3}{|c|}{ di-CQA treatment group } & \multicolumn{3}{|c|}{ tri-CQA treatment group } \\
\hline & & 6 hour & 12 hour & 24 hour & 6 hour & 12 hour & 24 hour \\
\hline $\mathrm{AcCoA}$ & 9.5 & 9.1 & 11 & 14 & 11 & 20 & 20 \\
\hline Citric acid & 646 & 428 & 528 & 468 & 1,453 & 1,266 & 1,276 \\
\hline cis-Aconitic acid & 29 & 21 & 31 & 21 & 61 & 62 & 56 \\
\hline Isocitric acid & 22 & 18 & 21 & 22 & 64 & 53 & 53 \\
\hline 2-OG & N.D. & N.D. & N.D. & N.D. & 2,228 & 1,195 & 1,424 \\
\hline Succinic acid & 1,460 & 1,574 & 2,207 & 2,469 & 6,019 & 5,601 & 4,290 \\
\hline Fumaric acid & 230 & 303 & 440 & 454 & 540 & 647 & 627 \\
\hline Malic acid & 1,088 & 1,472 & 2,058 & 2,185 & 2,665 & 3,039 & 3,101 \\
\hline
\end{tabular}

Abbreviations: AcCoA, Acetyl CoA divalent; 2-OG, 2-Oxoglutaric acid.

Table 3

Comparison of amount of identified metabolites including nucleotides in non-treated cells versus di-caffeoylquinic acid (CQA)-treated cells $(10 \mu \mathrm{M})$, and tri-CQA-treated cells $(20 \mu \mathrm{M})$ in SH-SY5Y. Concentrations of metabolites (pmol/10 ${ }^{6}$ cells) were identified by Capillary electrophoresis time-of-flight mass spectrometry (CE-ToFMS)

\begin{tabular}{|c|c|c|c|c|c|c|c|}
\hline \multirow[t]{3}{*}{ Metabolites } & \multirow[t]{3}{*}{ Control } & \multicolumn{6}{|c|}{ Concentration (pmol $/ 10^{6}$ cells) } \\
\hline & & \multicolumn{3}{|c|}{ di-CQA treatment group } & \multicolumn{3}{|c|}{ tri-CQA treatment group } \\
\hline & & 6 hour & 12 hour & 24 hour & 6 hour & 12 hour & 24 hour \\
\hline ATP & 5,099 & 4,051 & 6,047 & 7,169 & 5,218 & 5,877 & 7,413 \\
\hline ADP & 304 & 243 & 333 & 366 & 315 & 385 & 418 \\
\hline AMP & 34 & 24 & 36 & 39 & 38 & 48 & 57 \\
\hline GDP & 59 & 55 & 79 & 90 & 86 & 112 & 136 \\
\hline GTP & 727 & 540 & 935 & 1,397 & 796 & 1,185 & 1,858 \\
\hline
\end{tabular}

Abbreviations: ATP, adenosine-5'-triphosphate; ADP, adenosine- $5^{\prime}$-diphosphate; AMP, adenosine- $5^{\prime}$-monophosphate; GDP, guanosine- $5^{\prime}$ diphosphate; GTP, guanosine- $5^{\prime}$-triphosphate. 

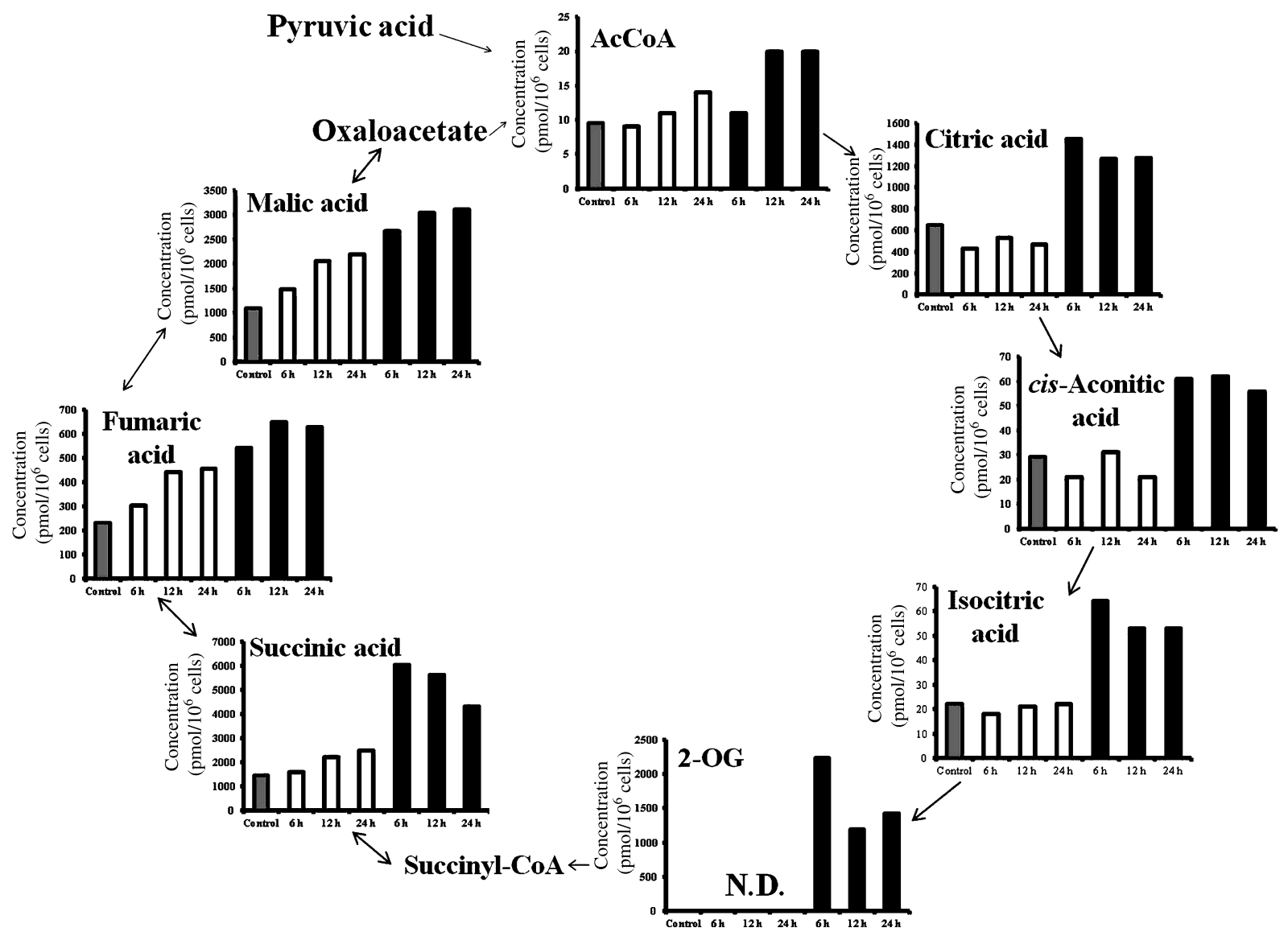

Fig. 3. Metabolome data map of tricarboxylic acid (TCA) cycle metabolites in non-treated cells (grey bars), $10 \mu \mathrm{M}$ of di-caffeoylquinic (CQA) acid-treated cells (white bars), and $20 \mu \mathrm{M}$ of tri-CQA-treated cells (black bars). Columns show amounts of metabolites (pmol/10 ${ }^{6}$ cells) determined by Capillary electrophoresis time-of-flight mass spectrometry (CE-ToFMS). Abbreviations: AcCoA, Acetyl CoA divalent; 2-OG, 2-Oxoglutaric acid.

metabolism in cells. It has been reported that a lower activity of glycolytic enzymes and a reduced level of pyruvate synthesis, pyruvate dehydrogenase activity, and acetyl CoA production have all been observed in the AD brain [39-41]. Furthermore, it has been reported that mildly impaired glucose availability in the synapse may impair cholinergic neurotransmission, a hallmark of AD [39, 42]. Consequently, the effects of di-CQA and tri-CQA in activating glycolysis and TCA cycle may provide some benefits in alleviating such deficits in AD.

tri-CQA was observed to be more effective than its di-CQA counterpart in inducing energy metabolism. This observation is consistent with previous research indicating that tri-CQA is a more effective in anticancer [43], anti-hyperglycemia [44], anti-HIV [45] agent. One reason for this may relate to the presence of the additional caffeic acid moiety. However, when assessing such effects in vivo, one must also consider the metabolism of these compounds. CQA is hydrolysed by intestinal microbiota into caffeic acid and quinic acid [46], with the absorption of CQA reported to be $33 \pm 17 \%$ and that of caffeic acid $95 \pm 4 \%$ in humans [47]. Indeed, administration of CQA leads to a significant increase in caffeic acid, but not CQA in the circulation, along with various caffeic acid glucuronides, and caffeic acid sulfates/glucuronides [48-50]. Whilst these derivatives are known to have stronger anti-oxidative activity, and higher intestinal absorption than CQA [51], caffeic acid does not appear to promote ATP production [18]. As such, the relevance of the current data should be considered in the context 
of this absorption data and further work is required to clarify the structure-function relationship on the activation of ATP production and energy metabolism in connection with neurodegeneration prevention.

The current work indicated that lactic acid was unchanged in response to di-CQA treatment. Lactic acid is generated from pyruvate and subsequently accumulates when anaerobic respiration is dominant [52]. The low level of PYR, and increases in AcCoA, succinic acid, fumaric acid, and malic acid suggest that there is an increased flux of the glycolytic pathway, which is transferred into the TCA cycle for further aerobic respiration via acetyl-CoA. On the other hand, tri-CQA treatment increases lactic acid and all TCA cycle metabolites suggesting activation of both glycolysis and TCA cycle. Both di-CQA and tri-CQA treatment induced increases in ATP, ADP, GTP, and GDP production, with the high levels of most nucleotide compounds indicating the relative promotion of cell growth compared to control group. As shown in a recent study, the nucleotide pools continuously decrease as the growth stage moves from the exponential to stationary phase in Escherichia coli [53].

In conclusion, results obtained in the present study indicate that energy metabolism is induced by diCQA and tri-CQA exposure of SH-SY5Y cells. This work emphasizes that the uptake of CQA-rich dietary sources may be beneficial against neurodegenerative diseases by improving age- and disease-related cellular energy deficiencies. Our data, suggest that although more work is required, these compounds mat represent a new treatment strategy to prevent some aspects of neurodegeneration and aging.

\section{Acknowledgments}

This study was partially supported by the project of Japan science and Technology Agency (JST) science and Technology Research Partnership for Sustainable Development (SATREPS).

\section{Abbreviations}

AcCoA, Acetyl CoA divalent; AD, Alzheimer's disease; ADP, adenosine-5' -diphosphate; AMP, adenosine-5'-monophosphate; ATP, adenosine-5'triphosphate; CQA, Caffeoylquinic acid; CE-ToFMS, capillary electrophoresis time-of-flight mass spectrometry; DHAP, Dihydroxyacetone phosphate; FBP, Fructose 1,6-diphosphate; F6P, Fructose 6-phosphate; GAP, Glyceraldehyde 3-phosphate; GDP, guanosine5'-diphosphate; GLC3P, Glycerol 3-phosphate; GTP, guanosine-5' -triphosphate; 2-OG, 2-Oxoglutaric acid; G6P, Glucose 6-phosphate; PEP, Phosphoenolpyruvic acid; 2-PGA, 2-Phosphoglyceric acid; 3-PGA, 3-Phosphoglyceric acid; PYR, Pyruvic acid; ROS, reactive oxygen species; TCA, tricarboxylic acid.

\section{Conflicts of interest statement}

The authors state no conflict of interest.

\section{References}

[1] Liu Y, Fiskum G, Schubert D. Generation of reactive oxygen species by the mitochondrial electron transport chain. J Neurochem. 2002;80(5):780-7.

[2] Harman D. The biologic clock: The mitochondoria? J Am Geriatr Soc. 1972;20:145-7.

[3] Selkoe DJ. Amyloid beta-protein and the genetics of Alzheimer's disease. J Biol Chem. 1996;271:18295-8.

[4] Beal MF. Energetics in the pathogenesis of neurodegenerative diseases. Trends Neurosci. 2000;23:298-304.

[5] Orth M, Schapira AH. Mitochondria and degenerative disorders. Am J Med Genet. 2001;106:27-36.

[6] Moro MA, Almeida A, Bolanos JP, Lizasoain I. Mitochondrial respiratory chain and free radical generation in stroke. Free Radic Biol Med. 2005;39:1291-304.

[7] Van Houten B, Woshner V, Santos JH. Role of mitochondrial DNA intoxic responses to oxidative stress. DNA Repair (Amst). 2006;5:145-52.

[8] Gonthier MP, Cheynier V, Donovan JL, Manach C, Morand C, Mila I, Lapierre C, Remecy C, Scalbert A. Microbial aromatic acid metabolites formed in the gut account for a major fraction of the polyphenols excreted in urine of rats fed red wine polyphenols. J Nutr. 2003;133: 461-7.

[9] Schroeter H, Heiss C, Balzer J, Kleinbongard P, Keen CL, Hollenberg NK, Sies H, Kwik-Uribe C, Schmitz HH, Kelm M. (_)-Epicatechin mediates beneficial effects of flavanol-rich cocoa on vascular function in humans. Pro Natl Acad Sci USA. 2006;103:1024-9.

[10] Auclair S, Milenkovic D, Besson C, Chauvet S, Gueux E, Morand C, Mazur A, Scalbelt A. Catechin reduces atherosclerotic lesion development in apo E-deficient mice: A transcriptomic study. Atherosclerosis. 2009;204:21-7.

[11] Morand C, Dubray C, Milenkovic D, Lioger D, Martin JF, Scalbert A, Mazur A. Hesperidin contributes to the vascular protective effects of orange juice: A randomized crossover study in healthy volunteers. Am J Clin Nutr. 2011;93:73-80.

[12] Scalbert A, Johnson IT, Saltmarsh M. Polyphenols: Antioxidants and beyond. Am J Clin Nutr. 2005;81:215-7. 
[13] Williamson G, Manach C. Bioavailability and bioefficacy of polyphenols in humans. II. Review of 93 intervention studies. Am J Clin Nutr. 2005;81:243-55.

[14] Spencer JP. Beyond antioxidants: The cellular and molecular interactions of flavonoids and how these underpin their actions on the brain. Proc Nutr Soc. 2010;69:244-60.

[15] Clifford MN. Chlorogenic acids and other cinnamates-nature, occurrence and dietary burden. J Sci Food Agric. 1999;79:36272.

[16] Han J, Miyamae Y, Shigemori H, Isoda H. Neuroprotective effect of 3,5-di-caffeoylquinic acid on SH-SY5Y cells and senescence-accelerated-prone mice 8 through the up-regulation of phosphoglycerate kinase-1. Neuroscience. 2010;169:1039-45.

[17] Miyamae M, Han J, Sasaki K, Terakawa M, Isoda H, Shigemori H. 3,4,5-tri-O-caffeoylquinic acid inhibits amyloid $\beta$-mediated cellular toxicity on SH-SY5Y cells through the upregulation of PGAM1 and G3PDH. Cytotechnology. 2011;63:191200.

[18] Miyamae M, Kurisu M, Han J, Isoda H, Shigemori H. Structure-activity relationship of caffeoylquinic acids on the accelerating activity on ATP production. Chem Pharm Bull. 2011;59(4):502-7.

[19] Oki T, Masuda M, Furuta S, Nishiba Y, Teruhara N, Suda I. Involvement of anthocyanins and other phenolic compounds in radical-scavenging activity of purple-fleshed sweet potato cultivars. J Food Sci. 2002;67(5):1752-6.

[20] Okuno N, Yoshimoto M, Yoshinaga Y. Reduction in analysis time by using short columns in HPLC determination of polyphenols in sweetpotato tops. Nougyougijutsu. 2008;63(9):413-7.

[21] Shimozono H, Kobori M, Shinnmoto H, Tsushida T. Suppression of the melanogenesis of mouse melanoma B16 cells by sweet potato extract. FSTR. 1996;43-3:313-7.

[22] Truong VD, Mcfeeters RF, Thompson RT, Dean LL, Shofran B. Phenolic acid content and composition in leaves and roots of common commercial sweetpotato (Ipomea batatas L.) Cultivars in the United States. J Food Sci. 2007;72:C343-9.

[23] Soga T, Heiqer DN. Amino acid analysis by capillary electrophoresis electrospray ionization mass spectrometry. Anal Chem. 2000;15;72(6):1236-41.

[24] Soga T, Ishikawa T, Igarashi S, Sugawara K, Kakazu Y, Tomita M. Analysis of nucleotides by pressure-assisted capillary electrophoresis-mass spectrometry using silanol mask technique. J Chromatogr A. 2007;3;1159(1-2):125-33.

[25] Sugimoto M, Wong DT, Hirayama A, Soga T, Tomita M. Capillary electrophoresis mass spectrometry-based saliva metabolomics identified oral, breast and pancreatic cancerspecific profiles. Metabolomics. 2010;6(1):78-95.

[26] Johnson SK, Houk LL, Johnson DC, Houk RS. Determination of small carboxylic acids by capillary electrophoresis with electrospray-mass spectrometry. Anal Chim Acta. 1999;389: $1-8$.

[27] Soga T, Heiger DN. Amino acid analysis by capillary electrophoresis electrospray ionization mass spectrometry. Anal Chem. 2000;72:1236-41.

[28] Soga T, Ueno Y, Naraoka H, Ohashi Y, Tomita M, Nishioka T. Simultaneous determination of anionic intermediates for bacillus subtilis metabolic pathways by capillary electrophoresis electrospray ionization mass spectrometry. Anal Chem. 2002;74:2233-9.

[29] Soga T, Ueno Y, Naraoka H, Matsuda K, Tomita M, Nishioka T. Pressure assisted capillary electrophoresis electrospray ionization mass spectrometry for analysis of multivalent anions. Anal Chem 2002;74:6224-9.

[30] Hirayama A, Kami K, Sugimoto M, Sugawara M, Toki N, Onozuka H, Kinoshita T, Saito N, Ochiai A, Tomita M, Esumi $\mathrm{H}$, Soga T. Quantitative metabolome profiling of colon and stomach cancer microenvironment by capillary electrophoresis time-of-flight mass spectrometry. Cancer Res. 2009;69: 4918-25.

[31] Scalbert A, Brennan L, Fiehn O, Hankemeier T, Kristal BS, van Ommen B, Pujos-Guillot E, Verheiji E, Wishart D, Wopereis S. Mass-spectrometry-based metabolomics: limitations and recommendations for future progress with particular focus on nutrition research. Metabolomics. 2009;5(4):435-58.

[32] Silverman DHS, Small GW, Chang CY, Lu CS, de Aburto MAK, Chen W, Czernin J, Rapoport SI, Pietrini P, Alexander GE, Schapiro MB, Jagust WJ, Hoffman JM, Welsh-Bohmer KA, Alavi A, Clark CM, Salmon E, de Leon MJ, Mielke R, Cummings JL, Kowell AP, Gambhir SS, Hoh CK, Phelps ME. Positron emission tomography in evaluation of dementia: Regional brain metabolism and Long-term outcome. JAMA. 2001;286:2120-7.

[33] Atamna H, Frey WH 2nd. Mechanisms of mitochondrial dysfunction and energy deficiency in Alzheimer's disease. Mitochondrion. 2007;7:297-310.

[34] Nicholls D. Mitochondrial bioenergetics, aging, and agingrelated disease. Sci Aging Knowl Environ. 2002;31:12.

[35] Biessels GJ, Kappelle LJ. Increased risk of Alzheimer's disease in Type II diabetes: Insulin resistance of the brain or insulin-induced amyloid pathology? Biochem Soc Trans. 2005;33:1041-4.

[36] Petit-Taboue MC, Landeau B, Desson JF, Desgranges B, Baron JC. Effects of healthy aging on the regional cerebral metabolic rate of glucose assessed with statistical parametric mapping. NeuroImage. 1998;7:176-84.

[37] Small GW, Bookheimer SY, Thompson PM, Cole GM, Huang SC, Kepe V, Barrio JR. Current and future uses of neuroimaging for cognitively impaired patients. Lancet Neurol. 2008;7:161-72.

[38] Yong SW, Yoon JK, An YS, Lee PH. A comparison of cerebral glucosemetabolism in Parkinson's disease, Parkinson's disease dementia and dementia with Lewy bodies. Eur J Neurol. 2007;14:1357-62.

[39] Sims NR, Bowen DM, Neary D, Davison AN. Metabolic processes in Alzheimer's disease: Adenine nucleotide content and production of $14 \mathrm{CO}_{2}$ from [U-14C]glucose in vitro in human neocortex. J Neurochem. 1983;41:1329-34.

[40] Sorbi S, Bird ED, Blass JP. Decreased pyruvate dehydrogenase complex activity in Huntington and Alzheimer brain. Ann Neurol. 1983;13:72-8.

[41] Bowen DM, White P, Spillane JA, Goodhardt MJ, Curzon G, Iwangoff P, Meier-Ruge W, Davison AN. Accelerated ageing or selective neuronal loss as an important cause of dementia? Lancet. 1979;1:11-4.

[42] Sims NR, Bowen DM, Davison AN. [14C]acetylcholine synthesis and $[14 \mathrm{C}]$ carbone dioxide production from 
[U-14C]glucose by tissue prisms from human neocortex. Biochem J. 1981;196:867-76.

[43] Kurata R, Adachi M, Yamakawa O, Yoshimoto M. Growth suppression of human cancer cells by polyphenolics from sweetpotato (Ipomoea batatas L.) Leaves. J Agric Food Chem. 2007;55(1):185-90.

[44] Matsui T, Ebuchi S, Fujise T, Abesundara KJ, Doi S, Yamada H, Matsumoto K. Strong antihyperglycemic effects of water-soluble fraction of Brazilian propolis and its bioactive constituent: 3,4,5-tri-O-caffeoylquinic acid. Biol Pharm Bull. 2004;27(11):1797-803.

[45] Tamura H, Akioka T, Ueno K, Chujyo T, Okazaki K, King PJ, Robinson We Jr. Anti-human immunodeficiency virus activity of 3,4,5-tricaffeoylquinic acid in cultured cells of lettuce leaves. Mol Nutr Food Res. 2006;50(4-5):396400.

[46] Gonthier MP, Verny MA, Besson C, Remesy C, Scalbert A. Chlorogenic acid bioavailability largely depends on its metabolism by the gut microflora in rats. J Nutr. 2003;133: 1853-9.

[47] Olthof MR, Hollman CH, Katan MB. Chlorogenic acid and caffeic acid are absorbed in humans. J Nutr. 2001;131(1):6671
[48] Azuma K, Ippoushi K, Nakayama M, Ito H, Higashio H, Terao $\mathrm{J}$. Absorption of chlorogenic acid and caffeic acid in rats after oral administration. J Agric Food Chem. 2000;48(11):5496500 .

[49] Gumbinger HG, Vahlensiek U, Winterhoff H. Metabolism of caffeic acid in the isolated perfused rat liver. Planta Med. 1993;59(6):491-3.

[50] Uang Y-S, Kang F-L, Hsu K-Y. Determination of caffeic acid in rabbit plasma by high-performance liquid chromatography. J Chromatog B. 1995;673:43-9.

[51] Sato Y, Itagaki S, Kurokawa T, Ogura J, Kobayashi M, Hirano $\mathrm{T}$, Sugawara M, Iseki K. In vitro and in vivo antioxidant properties of chlorogenic acid and caffeic acid. Int J Pharm. 2011;403:136-8.

[52] Buckstein MH, He J, Rubin H. Characterization of nucleotide pools as a function of physiological state in Escherichia coli. J Bacteriol. 2008;190:718-26.

[53] Hattori K, Kajimura M, Hishiki T, Nakanishi T, Kubo A, Nagahata Y, Othmura M, Yachie-Kinoshita A, Matsuura T, Morikawa T, Nakamura T, Setou M, Suematsu M. Paradoxical ATP elevation in ischemic penumbra revealed by quantitative imaging mass spectrometry. Antioxid Redox Signal. 2010;13(8):1157-67. 